\title{
Correction to: Prevalence and Clinical Predictors of Hyperuricemia in Chinese Bariatric Surgery Patients
}

\author{
Xiantu Qiu ${ }^{1} \cdot$ Longzhi Zheng $^{1} \cdot$ Bin $\mathrm{Zu}^{1} \cdot$ Benli Jia $^{2} \cdot$ Wei Lin $^{1,3}$ \\ Published online: 21 February 2022 \\ (c) The Author(s), under exclusive licence to Springer Science+Business Media, LLC, part of Springer Nature 2022
}

\section{Correction to: Obesity Surgery \\ https://doi.org/10.1007/s11695-021-05852-6}

The name of author Xiantu Qiu was spelled incorrectly.

Publisher's Note Springer Nature remains neutral with regard to jurisdictional claims in published maps and institutional affiliations.

The original article can be found online at https://doi.org/10.1007/ s11695-021-05852-6.

Benli Jia

benlijia@ahmu.edu.cn

$\triangle$ Wei Lin

linwbj@outlook.com

1 Department of Gastrointestinal Surgery, The Affiliated Hospital of Putian University, Putian 351100, China

2 Department of General Surgery, The Second Hospital of Anhui Medical University, Anhui 230601, China

3 The Third Clinical Medical College of Fujian Medical University, Fuzhou 350001, China 